\title{
Pranking in children's helpline calls
}

Ann Weatherall, Susan Danby, Karin Osvaldsson, Jakob Cromdal and Michael Emmison

\author{
Linköping University Post Print
}

N.B.: When citing this work, cite the original article.

This is an electronic version of an article published in:

Ann Weatherall, Susan Danby, Karin Osvaldsson, Jakob Cromdal and Michael Emmison, Pranking in children's helpline calls, 2016, Australian Journal of Linguistics, (36), 2, 224-238. Australian Journal of Linguistics is available online at informaworld ${ }^{\mathrm{TM}}$ :

http://dx.doi.org/10.1080/07268602.2015.1121532

Copyright: Taylor \& Francis (Routledge): SSH Titles

http://www.routledge.com/

Postprint available at: Linköping University Electronic Press

http://urn.kb.se/resolve?urn=urn:nbn:se:liu:diva-125712 


\section{Pranking in children's helpline calls}

Ann Weatherall ${ }^{1}$, Susan Danby ${ }^{2}$, Karin Osvaldsson ${ }^{3}$, Jakob Cromdal $^{3}$ and Michael Emmison ${ }^{2}$

${ }^{1}$ Victoria University of Wellington, New Zealand

${ }^{2}$ Queensland Institute of Technology, Brisbane, Australia

${ }^{3}$ Linköping University, Sweden

Address for correspondence:

Ann Weatherall

School of Psychology

Victoria University of Wellington

P.O. Box 600

Wellington

New Zealand

Ann.Weatherall@vuw.ac.nz

Telephone: +644635211

Keywords: Conversation analysis, counselling, hoax, identity, membership categorisation, YouTube.

Word Count: 6995

\section{Acknowledgements}

Some of the calls used in this paper were collected as part of a project that investigated clientcounsellor interactions on Kids Helpline, which was supported by an Australian Research Council under Discovery grant (Project ID: DP0773185) with ethical approval from Queensland University of Technology. We thank Kids Helpline and BoysTown, and the counsellors and clients who took part in the study. 


\section{Abstract}

Pranking can be understood as challenging a normative social order. One environment where pranking occurs is in institutional interaction. The present study examines a sample of pranking calls to telephone helplines for children and young people. Some cases had been posted on YouTube by the person doing the pranking; others were from a sub-collection of possible pranks, extracted from a larger corpus of Australian children's counselling helpline calls. Drawing on ethnomethodology and conversation analysis we aim to understand the inferential and sequential resources involved in pranking within telephone-mediated counselling services for children and youth. Our analysis shows pranksters know the norms of counselling helplines by their practices for subverting them. YouTube pranksters exploit next turns of talk to retrospectively cast what the counsellor has just said as a possible challenge to the perception of the call as a normal counselling one. One practice evident in both sources was the setting-up of provocative traps to break a linguistic taboo. This detailed study of pranking in interaction provides documentary evidence of its idiosyncratic yet patterned local accomplishment in telephone mediated counselling services aimed at children and youth. 


\section{Pranking in children's helpline calls}

\section{Introduction}

Pranking is a recognisable social practice. One high profile prank was conducted by Australian radio presenters who posed as members of the British royal family in a call to a hospital (The Lamp, 2013). Their ruse successfully elicited personal information from a nurse about the Duchess of Cambridge's health. Tragically, the nurse who took the call later committed suicide. Pranks share an attempt to dupe, trick or deceive. They break a mutual trust in a shared perception of a world-in-common that ethnomethodology has established underpins the routine production and maintenance of everyday activities (Garfinkel 1963). An aim of the current research is to elucidate practices for doing and managing pranking in a particular interactional setting - that of hoax calls to institutions that offer telephone-mediated counselling services for children and youth.

Institutional interactions, typically proceed on the background assumption that both parties are engaged in accomplishing the relevant business of the organisation. Garfinkel (1967) called the assumption of a joint understanding a 'natural attitude' towards the social world. Discussing Garfinkel's work on the routine as an accomplishment, Heritage (1984) noted that a natural attitude underpins "perceived normality" (p. 82) - that is, the perception of what is happening in the hereand-now of the interaction as business-as-usual.

Garfinkel's (1967) series of breaching experiments insightfully highlighted elements of the natural attitude that underpin a joint understanding of a reality shared in common. For example, in a game of tick-tack- toe (also known as naughts and crosses) an experimenter's confederate was instructed to break the rules of play by rubbing out and moving their opponent's mark. Garfinkel found that these engineered departures from the background expectation of game playing-as-usual resulted in attempts by the unknowing party to restore "a right state of affairs" (Garfinkel 1967:42) by treating what was happening as, for instance, a joke or as a different game. Another breaching experiment involved one person requesting the inferred meanings of another party's talk be made 
explicit. That study clearly showed that everyday interaction requires a considerable amount of inference for understanding what is being meant and done from what people say.

Documenting the way the inferential order works in everyday sense making and in the joint accomplishment of action is the intellectual project of membership categorisation analysis (Butler \& Weatherall 2006; Hester \& Eglin 1997; Sacks 1972, 1992; Stokoe 2012). The approach has established, for example, a close inferential relationship between category memberships and the activities and attributes that are associated with them; for example, a well-known example is Sacks' (1992, Vol 1: 236) discussion of 'the baby cried. The mummy picked it up'. In institutional talk participants assume the relevance of institutional membership categories, which are inferentially rich. The relevant category memberships for parties in counselling helpline interactions are helpseeker (caller) and help-giver (counsellor). Pranking as an action in helpline calls relies on the helpseeker and help-giver relationship but also draws on an alternative characterisation of it, which is, the prankster and the duped. The epistemic domain (Heritage 2013) is clearly important to pranking because the prankster has considerable authority and control in constituting a local reality as a hoax. Once pranking is revealed, the interpretative frame shifts and understanding of the relevant category membership change (e.g., from caller to prankster) and the social meaning of their actions can change (e.g. from genuine help-seeking to attempting to dupe).

Prank calls to institutions that offer telephone-mediated help are a frequent occurrence. Counselling helplines for children and youth - the focus of our present study - report that they are very common. For example, the Australian Kids Helpline estimated at least 60 percent of their calls require no counselling support (Emmison \& Danby 2007). Despite the high frequency of pranking calls, few studies have examined how pranking is actually accomplished, recognised and managed in interaction. Seilheimer (2011) studied pranking from the pranksters point of view, looking especially into what it takes to be an expert in that community of practice, which is constituted in part though linguistic practices shared by those who have a social identity as a prankster . Another notable exception to the lack of studies on pranking is Emmison and Danby (2007) who found that Australian 
Kids Helpline counsellors drew on specific interactional strategies when they suspected that a call may be a prank. Counsellors typically announced their suspicions indirectly, for example, by asking if there was a friend in the background. Sometimes that inquiry prompted the caller to reveal that it was a hoax. At other times, the inquiry led to an explanation that supported the genuineness of the call (such as having an older sister nearby for support).

A regular aspect of pranking identified by Emmison and Danby (2007) was that the caller attempted to engineer a situation in which the adult counsellor was required to use sexual or scatological words. Emmison and Danby showed how counsellors skilfully avoided 'talking dirty' without rebuking or challenging callers. One way the counsellors managed this was by reversing the direction of questioning. For example, when one caller asked what the hairs growing on parts of her body were, the counsellor asked the caller what she thought was happening. This countering move can provide the counsellor with an opportunity to hear what the caller knows about the matter.

Australian Kids Helpline policy categorises prank calls as 'testing', because they work from the premise that the young people may be experimenting or learning how to seek help (Barton 1999). Calls are classified as possibly 'testing' if they have a sexual or scatological theme or if there is a friend in the background. Counselling - talk elicitation, listening and facilitating the caller to formulate their own solutions - is provided regardless of the whether a call is 'testing' or not.

In this study we examine a sample of children and young persons' pranking calls to telephone-mediated counselling helplines. Our goal is to illuminate how pranking is accomplished, recognised and managed. The analytic focus is on the interactional structures and inferential practices that construct or contest the call as a prank. We aim to contribute to an understanding of how pranks are achieved as a social action and consider the implications of our work telephonemediated counselling services.

\section{The data and methodology}


The data for this paper were drawn from two data sources: YouTube clips and audio-recorded calls to Kids Helpline, Australia. The YouTube clips were identified by searching with the keywords 'prank', 'children' and 'helpline' in 2009. These clips were seemingly posted by the ones doing the calling and most included a video of the prankster making the hoax call. The callers self-nominated to upload their video episodes as 'prank' in their keyword descriptors - so treating these calls as pranks is not an analyst's construct but a participant's emic description. In total, 6 clips were identified and downloaded. It is not possible to be completely sure of the actual service, or the details of the service, that was contacted. It appears, however, that two were from the Australian Kids Helpline, and the remaining were North American counselling helplines for either children or young people, or for suicide prevention. The videos have since been removed from YouTube - what was the link now results in a message that the video has been removed as a violation of policy prohibiting content designed to harass, bully or threaten.

The second source of data was Kids Helpline - an Australian counselling helpline for children and young people up to the age of 25 years staffed by paid professional counsellors. Ethical clearance for collecting phone, online chat and email counselling data was obtained through Kids Helpline/BoysTown and Queensland University of Technology. The focus was on phone counselling calls, specifically drawing on 8 'testing' calls within a larger corpus of 52 phone calls. Episodes selected for close analysis in this paper were those that showed the clearest examples of the pranking phenomenon and a range of practices.

The study draws on conversation analysis and membership categorization analysis to understand the organisation and management of pranking in calls. Calls were transcribed using Jeffersonian (2004) notation that allows for close examination of details such as overlapping talk, laughter, and silences. These features of social interaction are relevant for understanding how people do things in interaction, such as pranking in interaction. While pranking is a broader social phenomenon, the focus in this paper is an investigation of its accomplishment in a dyadic, 
telephone- mediated institutional interaction. The analysis shows how pranking both depends upon and challenges the normative social order that produces an interaction as doing counselling.

\section{Analysis}

Extracts $1-3$ are taken from the same YouTube call. The pranking nature doesn't make it to the interactional surface explicitly; that is, neither the caller nor the call-taker (a Kidshelpline counsellor) name what is happening as a prank. In this case our analysis of the call as a prank rests on its description as such by the person that uploaded the video onto YouTube. Extract 1 is taken from the beginning of the call. What can be seen is the caller $(\mathrm{CL})$ interpreting what the call-taker $(\mathrm{CT})$ says literally rather than displaying an understanding of implicit meaning.BG refers to person in the background.

Extract 1 You Tube "prank to kidshelpline"

๑3 CT: Hello this is kidshelpline. May I help you?

$\odot 4$

$(0.6)$

05 CL: Yes you can.

$\odot 6$

$(\odot .7)$

07 CL: I- I'm emotionally depressed and feeling really

$\odot 8$ $>$ suici<dal.

$\odot 9$

$(\odot .6)$

10 CT: $0:{ }^{\circ} \mathrm{kay}:{ }^{\circ}$

11

$(\odot .4)$

$12 \mathrm{CL}$ : (breathing into phone)

13 BG: (clears throat)

14

CL: N:o, it's no:t o:kay.

15

$(0.6)$

$16 \mathrm{KL}$ : I mean would you li:ke to talk abou-its okay to talk about those things. 
The counsellor call-taker opens the interaction by giving their institutional identification and asking May I help you. That opening is non-routine, at least for the Australian Kids Helpline, where such formulations in call openings are avoided because their business is to 'care' and 'listen' rather than to 'help' (Danby Baker \& Emmison 2005). A more typical opening would be a greeting with an institutional identification (Emmison \& Danby 2007). Nevertheless, questions such as How may I help you? or What can I do for you? in institutional contexts are routinely understood as functioning to solicit presenting concerns (Robinson 2003). In the above extract the caller responds to the solicitation May I help you literally. The response yes you can (line 05); the caller's granting of permission construes the previous turn as a request for permission, and not as a solicitation for talk. The literal interpretation of the counsellor's question May I help you is a violation of a routine way of understanding such utterances in institutional talk. The failure to make a normative inference about the meaning and action of the utterance is an action akin to Garfinkel's (1967) breaching experiment where one party requested the implicit meanings of another party's utterance be made explicit. In the above case the counsellor does not respond to the breach in perceived normality and, after a short silence (line 06), the caller continues by presenting his concerns. That is, he discloses his problem - he is feeling depressed and suicidal. By describing his problem he demonstrates his understanding that the counsellor was soliciting his reason for calling the counselling helpline.

A second instance where the caller misconstrues the call-taker's action occurs after line 07, when the caller presents his concern as being depressed and suicidal. The call-taker uses okay in the third turn of the talk-solicitation sequence to register and accept the caller's turn. Okay is regularly used in the third turn of an adjacency pair sequence as a way of accepting a response without displaying any particular stance towards it (see Schegloff 2007). It seems reasonable to suggest that, in this case, the okay receipts the problem as one fitted to the service offered by the helpline. The caller treats the call-taker's okay at line 10, however, as an assessment of his depressed and suicidal 
state - and out-rightly rejects it by disagreeing No it's not okay. The call-taker's next turn treats the caller's disagreement as a trouble with understanding. She addresses the misunderstanding by clarifying that she meant that it's okay to talk about depression and suicidal feelings (lines 16-17). The use of third position repair (Schegloff 1992) is a practice that speakers can use when a recipient misunderstands what they have said. The call-taker is doing reassurance that it is appropriate to talk about the issues of suicidal feelings and, through this strategy, maintains the interaction as a call to a counselling helpline. The call-taker's move to normalise departures from a perceived normality is a strategy that was originally identified by Garfinkel (1967) to restore a joint understanding of a local reality. Another way that the caller in the YouTube prank challenges the perceived normality of the call is illustrated in Extract 2. Beginning in line 19, the caller complains about the "hold music" that he listened to while he was waiting to be connected with a call-taker.

\section{Extract 2 You Tube "prank to kidshelpline"}

19 CL: That's why I rang here, =and first of all

20 $(\odot .2)$ (click) $>$ seriously< $(0.4)$ the Hold music $(0.4)$ it makes me feel w:o:rse. Hh $(0.4)$

CT: aw:h I'm sorry about that. $(\odot .6)$

$C L: \quad<i t^{\prime} s>(0.5)$ I'm not even Indian. hhh (sniff) $(0.4) \mathrm{N}-$

come on a- hhh $(0.4)$ that's just ter:rible hh

CT: o kay.

$$
(0.5)
$$

CT: .hh I'll try to pass that message on. $(0.4)$ 
$33 \mathrm{CL}$ : Thank you: hh .hh

34 $(\odot .2)$

35 СT: So tell me about >you know< more about 36 how you're feeling tonight.

37 $(\odot .2)$

38 CL: Like sh::it. hh

One element to the complaint is about the music the caller had to listen to while he was waiting to be connected to a counsellor. He makes a complaint that the music aggravates the way that he is feeling and that the music is not a good cultural fit. Close to the beginning of this complaint is the parenthetical stance marker seriously (line 21), which functions as a kind of disclaimer - displaying that what is to follow could be interpreted as non-serious. The caller then suggests that the hold music - a mundane aspect of the setting that the helpline is responsible for - is detrimental to him. A second element of the complaint is that there is not a good cultural fit between the music and the caller - I'm not even Indian. The ethnic categorisation potentially introduces a racist element that a natural attitude may deem transgressive or provocative. The call-taker does not further the relevance of the ethnic identity of the caller.

Challenging or criticising the organisation in the problem presentation phase of a helpline is potentially another breach of the perceived normality of a counselling helpline call. The call-taker, however, treats the complaint as relevant information for the organisation by receipting it and giving an apology for that (line 24), saying that she will pass the message on presumably to someone whose institutional role includes responsibility for matters such as the hold music and/or complaints about it. It is a strategy that was also seen in extract 1 - a move that works to maintain the perceived reality of the call as a normal counselling one. The caller expresses appreciation that the call-taker will pass on his message, which supports a joint understanding that the aired complaint had been adequately addressed. 
After the complaint sequence closed, the call-taker returns to counselling work by asking the caller to disclose more about his feelings - an activity that is inferentially bound to a person seeking help from a counselling helpline. In response to the talk elicitation request, the caller gives a relevant, albeit rather terse, response. At this moment in the call, both parties seem to be displaying a natural attitude to the call as a counselling one.

Extract 3, from the same call as the previous two extracts, begins with call-taker again prompting the caller to talk more about his feelings. The caller's response is another instance from this call where a mutual trust in the perceived normality of the counselling helpline call is potentially challenged by the caller's response to the talk elicitation question - you need to know more about suicidal feelings?:

Extract 3 You Tube "prank to kidshelpline"

77 Ст: [(typing)] o- $\mathrm{k}[$ ay $(0.4)]$ so: tell me some more=

$78 \mathrm{CL}: \quad[\mathrm{hh}]$

79 СТ: =about those feelings?

80 $(0.6)$

81 CL: hh: :

82 $(\odot .6)$

83 CL: uh:m: : you need to know more about suicidal feelings?

85 CT: we:ll I need to know more about your feelings. 86 $(1.2)$

$87 \mathrm{CL}$ : ah well they're a little su:icidal.

88

$$
\left[\begin{array}{lll}
(2.4 & 2.4
\end{array}\right]
$$

89 CL: [(breath tokens $)]$

90 СT: alright

91 $(0.6)$ 
92 СT: so say a bit more about that, if you don't mind.

A core task for counsellors is talk-elicitation (see Peräkylä, Antaki, Vehviläinen and Leudar 2008). At lines 77-79, the call-taker is clearly engaged with that elicitation work when she says so tell me some more about those feelings. The caller seeks confirmation of that request at lines $83-84$. The confirmation has the form of a modified repeat, which works to interpret the request as being one about suicidal feelings in general. Stivers (2004) found that modified repeats can function to compete with the prior speaker's right to socio-epistemic authority. Although her cases were in response to assertions, a similar practice seems to be operating here. The caller is calling into question the call-taker's authority as a counsellor by seeking confirmation, when it is not otherwise relevant, about her need to know more about suicidal feelings - presumably something a helpline counsellor would have professional knowledge about.

The caller's challenging question unsettles a background expectation that the call is counselling-as-normal. The call-taker moves to normalise the potential further disruption by correcting the caller's interpretation, saying it is his personal feelings she is interested in - not suicidal feelings in general. The caller's brief response well they're suicidal provides a relevant response. The call-taker receipts that response with alright and then asks for further elaboration again, which treats the caller's response as inadequate. The call- taker's repeated requests for further talk is evidence that she is orienting to the call as other than business-as-usual. In the above extract, as in the previous ones, the caller is using a response slot to breach the background expectation that questions will be understood as doing counselling.

The next extract is from a different call posted on YouTube - this one to a suicide helpline. In the following case, we see the caller setting up a provocative kind of trap and then pursuing an explicit acknowledgment of it, which is not provided. The extract below begins where the recording posted on YouTube starts. 
Extract 4 YouTube prank to suicide helpline

$08 \mathrm{CL}$ : Now- if I smoke one more cigarette $(0.6) \mathrm{I}^{\prime} \mathrm{m}$

๑9 gonna slit my wrist-.

$10 \quad(0.8)$

11 CT: Don't do tha: t

$12 \mathrm{CL}$ : I'm not $I^{\prime} m$ not being all that serious but $I^{\prime} m$

14 CT: Oh okay. You're you're saying that $(0.6) \mathrm{Um}$.

15 not that you mean it.

$16 \quad(0.6)$

$17 \mathrm{CL}$ : No. but I'd probably just go snort a couple lines

18 of coke or something.

$19(\odot .7)$

20 СТ: Oh well that's hurting yoursel: $f$

$21 \mathrm{CL}$ : No it's not- >Hold on< can you hold on one second?

$(0.6)$ (long sniff) (๑.6) (cough cough)

23 СТ: 0- okay can you (0.4) not do that please:?

24 $(0.6)$

$25 \mathrm{CL}$ : w-oh- What are you talking about?

26 CT: What did you just do?

27 CL: I just >blow on< my nose.

28 $(0.4)$

29 СT: oh okay.

30 CL: Why? > What did you< think I did. $(0.5)$

32 CT: Well what you said you were gonna do.

$33 \mathrm{CL}$ : What was that again?

34

$(1 . \odot)$ 


\section{CT: Have you ever attempted suicide in the past:?}

At the beginning of Extract 4, the caller proposes that smoking a cigarette (line 08) could incite him to slitting his wrists - a suicidal behaviour. The call-taker responds by a directive - she asks him not to do it. For suicide helpline counsellors, dissuading callers from suicidal behaviours is an activity predicated on their category membership. In the following turns, the caller provides clarification that he is not really intending to harm himself by giving the call-taker an assurance that he was not being serious about slitting his wrists (line 12).

The caller suggests an alternative course of action that he might take in response to his cigarette-smoking - snorting cocaine (coke). The call-taker responds by pointing out that taking cocaine is also a form of self-harm. The caller disagrees with that view, no it's not, and then interrupts the interaction by saying hold on, followed immediately by sniffing and coughing sounds. The call-taker's response, can you not do that please?, displays her understanding and stance that he is doing something he shouldn't. The indexical that refers to the cause of the sniffing and coughing. There are a variety of explanations for sniffing and coughing but the most locally available interpretation of what 'that' could refer to, in this instance, is taking cocaine (lines 17-18).

The caller does not respond to the requesting action, but instead he seeks clarification of what the that refers to; he asks What are you talking about? He is being deceptive because he does know what the caller is referring to. By claiming the call-taker's previous turn doesn't make sense, the caller both challenges and delays responding to the call-taker's directive. The call-taker, rather than clarifying her earlier turn, instead counters this by seeking an account of what he has done. This turn by the call-taker shows her backing down from her earlier stance to one of potentially being unknowing about the cause of the coughing and the sniffing.

In response to the call-taker's question that asked him to explain the cause of the sounds he made, the caller says he was just blowing his nose. The just in his response minimises his previous actions heard by the call-taker, which rhetorically works up his innocence. Further, at line 30 , the 
caller questions the call-taker's motivation for calling him into account when he says why? what did you think I did?. The call-taker explicitly explains, without actually naming what she thought, by saying, what you said you were gonna do. The caller asks for a third time what that refers to, which shows him to be pursuing some kind of utterance that directly refers to taking cocaine. In sum, the caller sets up a trap into a taboo by misconstruing his action and then holding the call-taker accountable for it.

The analysis of Extract 4 presented so far has described the way that the caller pursues, via a series of questions, a response where the call-taker will lured into a locally construed taboo of 'drug taking talk'. Following the caller's asking for the third time, What was that again, there is a one second silence. It is the call-taker's turn to talk, but there is a noticeable absence of response (line 34). In this case, the pursuit ultimately fails. The call-taker does not address his question but instead shifts to normalise the action by moving to a relevant helpline activity, designed to diagnose risk Have you ever attempted suicide in the past?. This extract highlights how trust in a shared perception of a world-in-common can be challenged and re-established. It provides a compelling example of pranking as breaching the normative expectation of a shared reality.

In the above extract, there was a trap set to lure the call-taker into a locally construed taboo that would have the call-taker say the caller was snorting coke. The trap was accomplished sequentially. There was a set-up, where the caller says he might engage in an undesirable behaviour, and then does something that is hear-ably that behaviour. After the trap was successfully set, the caller asks for explicit confirmation of it from the call-taker. A similar sequential structure is evident in the next extract. A young caller to Kids Helpline says he is scared of a big black dog staring at him, with a big long thing underneath its bottom (talk not shown in the transcript). The extract begins as the caller further describes the appendage, and asks the call-taker about it (line 58).

Extract 5 call 5_1_51 (Emmison \& Danby, 2007)

$55 \mathrm{CL}$ : it keeps wobbling $(0.5)$ around 


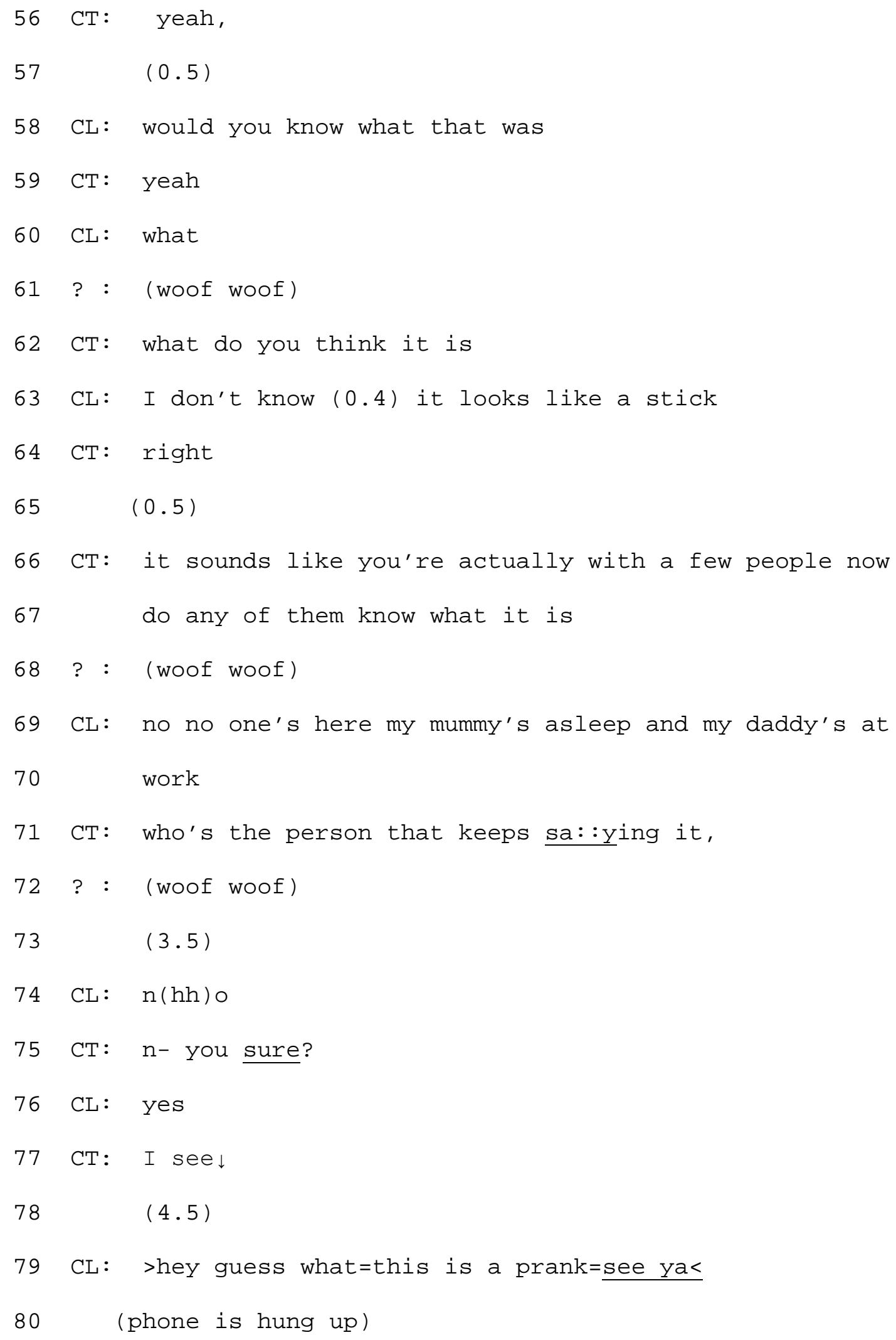

Emmison and Danby (2007) suggested that a regular feature of pranking is that callers try to get the counsellor to 'talk dirty'. In the above extract, the child sets a trap into the linguistic taboo by asking 
the call-taker directly whether she knows what that is (line 58). She replies that she does, with a simple yeah response. Treating the question simply about her state of knowledge provides a relevant response. The caller's follow up question, what, which is a clearly a pursuit for a label; in this instance, of a genital area. Evident in line 62 is the call-taker's skilful resistance to providing the sought-for sexual terminology, which she does by mobilising a counter (Schegloff 2007). Her counter hands the conversational floor back to the caller. In this case, the caller claims insufficient knowledge to answer, offering a further description of what the anatomy in question looks like.

At line 66 , the call-taker orients to the possibility of a prank by asking about the others in the room but she does not outwardly challenge the genuineness of the call. Also, she uses that inquiry as a resource to suggest a way for the caller to get the information. The caller denies that there is anyone there (line 69-70), and he provides an account for the absence of his parents. His account is consistent within the membership category of a child who is vulnerable and might need the services of the helpline because the usual people to turn to for help are not there (Sacks 1972).

From line 66, the caller's pursuit of getting the call-taker to 'talk dirty' seems to have been abandoned. In line 71, the call-taker rejects the caller's account by asking who's the person who keeps saying it. The indexical it assumes that both parties know what it is referring to, which is the woofing sound heard in the background of the call. This question shows the call-taker's understanding that there is no real dog but rather a human imitating the sound of a dog. The woofing sound at lines 68 and 72 seem to be coordinated and follow on from the call-taker raising the possibility of others being in the room. After a 3.5 second silence, the caller responds to the further probing by the call-taker about who is there, with a single word denial at line 74 , although his denial is accompanied with laughter particles. The call-taker responds immediately by asking if the caller is sure, which shows her continued scepticism of the caller being alone. The confirmation of the certainty with yes furthers his denial of the truth of the call-taker's understanding. She receipts this with I see, which claims understanding and seems to indicate her acceptance that the caller will not concede to her version of what is happening. At this point, and after a 4.5 second silence, the 
prankster concedes to the façade - announcing the call was a prank and then unilaterally closing the call. The swift move to call closure when the caller recognises the call-taker suspects a prank occurred in two other cases. In the next and final extract the call-taker questions the genuineness of the caller with a different outcome. The analysis highlights how challenging the caller and treating the call as non-genuine is a delicate matter that can backfire.

Extract 6 YouTube prank to suicide helpline

52 CL: >can you can you< answer, is it poss:ible to

53 commit suicide with a ketchup packet?

54 $(1.4)$

55 CT: How do you mean:?

56 $(0.6)$

57 CL: I >don't know<. (0.5) I'm >tryin'

58 na< be [ creative ]

59 CT : $\left[{ }^{\circ}>\right.$ is this $\left.a^{\circ}<\right]$ serious phonecall?

60 $(0.6)$

$61 \mathrm{CL}$ : of [cour:se this is serious? I'm calling the= 62 =serious]

63 CT: [indistinguishable murmur]

64 CL: suicide am I calling a joke ser- like u:m (0.4)

65 what's it called? Suicide hotline.

$66 \quad(0.3)$

$67 \mathrm{CL}$ : Is this the suicide hotline for joking?

68 CT: I- I hope not: : .

69 $(0.5)$ 
The beginning of Extract 6 begins with the caller asking whether it is possible to commit suicide with a ketchup packet. Unlike wrist slitting (see Extract 4), ketchup packets are not immediately associated with suicide attempts. The call-taker's response evidences the tenuous relevance of packaged ketchup in two ways. First, she asks what the caller means (line 55), which is responded to with a claim to insufficient knowledge, and an account that he is trying to be creative. The call-taker treats the original question and his response to her question as possible evidence that the call is not serious, which is shown in her accusation is this a serious phone call (lines 58-59) that the caller denies, of course this is serious.

The caller's denial is followed by his formulation of the helpline service as a suicide hotline for joking. The caller's question makes sense because it rests on a shared understanding that legitimate calls are produced by an aligning relationship between the reason for the call and the service provided. Thus, for the caller to be legitimately joking, he must be calling a joking helpline. The flipside is that the call-taker is a counsellor for a serious suicide helpline - thus to maintain the helpline as a serious one, the call-taker is responsible for treating the caller as serious.

The caller in Extract 5 uses the principle of consistency between members of a category and action (Sacks 1992) to challenge the normative helpline relationship between caller and call-taker. The caller troubles the interaction in a way that highlights the normative interpretative order upon which the successful accomplishment of the business of a suicide helpline rests. It shows that, for a legitimate call, the identities of the call-taker and caller are what Sacks (1992) describes as a standard relational pair; that is, the caller is a client seeking the support of a call-taker/counsellor, so the standard relational pair is counsellor - client. A joking trouble presented by a caller properly could be directed to a call-taker who deals with non-serious matters. The call-taker, by denying the call is a prank, resists the alternative formulation to instead maintain the normative interpretative order.

The classification of a call as pranking is a relevant matter for both parties to the call. The call-takers competence relies, in part, on being able to show they are not being duped. A displayed 
orientation by the call-taker to the call as a pranking one is procedurally consequential, as the above two extracts illustrated.

\section{Discussion}

Our analysis identified and described some practices for doing pranking in a sample of counseling helpline interactions drawn from different but related sources. The YouTube examples showed how callers exploited a fundamental structural feature of interaction- a next-turn-of-talk displays an understanding of the prior one. We found that the understanding displayed by the self-identified prankster could plant a 'possible' trouble. In extract 1 there were two plants of possible trouble responding to a question designed to elicit talk May I help you as if it was asking an information question yes you can and interpreting the receipt token okay as if it was a positive assessment of the caller's turn and using it to disagree no, it's not $O K$. The trouble is only a possible one because recurrently the call-taker would do nothing (waiting for the caller to say more) or treat the possible trouble as a problem in understanding and move to correct it (e.g. I mean it okay to talk about those things). Waiting for the caller to continue speaking and correcting are normal actions for counsellors. In terms of the interaction, the call-taker is doing what Garfinkel (1967) described as restoring things to a right state of affairs.

The literal interpretation of the call-takers' utterances is a source of possible trouble because it breaches a natural attitude that is normatively held. According to Garfinkel (1963) mutual trust in a shared perception of a world-in-common is part of a natural attitude that underpins the seamless accomplishment of routine activities. Different perspectives on the local interactional reality can result in an interpretative shift - in our cases the call-taker could infer the call was not genuinely help-seeking or the caller could realize the call-taker suspects the caller's deception. An inference could be articulated explicitly, for example, by asking if it is a serious call or available implicitly by assuming a friend in the background. By violating a background expectation that the call is a counseling one, the caller shows they know about normative order and how that can be disrupted. 
A practice that was seen across the different sources of data was the setting up of provocative traps to get the call-taker to say something that was construed as a kind of taboo. The YouTube case shown in Extract 4 was a sophisticated example where the caller set-up a situation where the call-taker would say she thought the caller was snorting cocaine in the here and now of the call. A similar strategy was observed in a young child's call to Kids Helpline (Extract 5) where the caller tried to get the call-taker to explicitly name the genitals of a dog. That the same kind of sequence was observed in two different sources of hoax calls supports a claim that is a recurrent practice for doing pranking. The differences between the two sources (e.g., the older more sophisticated prankster in the YouTube case (Extract 4)) shows that YouTube clips of prank calls are a particular kind of data - produced for that medium, which may be more or less like prank calls that were not uploaded onto YouTube.

An analytic problem with doing research on pranking is defining a call as a prank when there is no explicit disclosure of it as such. In the audio recorded calls to Kids Helpline cases were collected as examples of possible pranks because there was an displayed ambiguity between the caller and call-taker whether the call was a genuine counseling call or not. The ambiguity of the intended purpose of the call justifies, we think, the institutional policy of Kids Helpline to treat all calls as genuine, even if they are testing. If callers are troubling the interaction by undermining the caller's trust in them as a help-seeker, it gives the call-takers an opportunity to display their professionalism.

The cases drawn from YouTube were justified on the basis they had been described as pranks by the party posting the video. However, analyzing those as representative of pranking practices in children's helpline calls is somewhat problematic. For example, as already mentioned, some of the YouTube pranksters seemed to be older and more intent on undermining the professional integrity of the counsellor than the Kids Helpline cases.

The methodological approach used in this paper was to treat pranking as an action that was accomplished by disrupting a normative social order produces a routine telephone counselling service interaction. Of course, not all pranks are contained within bounded interactions. Some, such 
as the hoax concerning the British royal family, develop into a social object in its own right. Analyses of the broader cultural conditions that produce particular pranks require a different analytic approach. For example, Seilheimer (2011) investigated prank callers as a community of practice, providing insights into what it takes to be an expert prankster. Some of the calls in this paper had been posted by callers as hoaxes on YouTube, which supports the idea of pranksters as a shared identity constituted in part by social and linguistic practices.

Pranking is a wide-spread recognisable action. A much broader range of interactions where pranking is done need to be studied before we can be sure to have captured the full diversity of interactional practices that are used when engaging on the practices of pranking. Nevertheless, our work contributes to an understanding of pranking by investigating its accomplishment in the setting of calls to institutions offering telephone-mediated counselling for children and young people.. 


\section{References}

Barton A 1999 Prank calls: Plague or purpose? Kids Helplines Newsletter, March.

Butler C W \& Weatherall A 2006 “"No we're not playing families” Membership categorization and children's play' Research on Language and Social Interaction 93 (4): 441-470.

Danby S, Baker C D \& M Emmison 2005 'Four observations in openings on calls to Kids Line' in Baker C D, Emmison M \& A Firth (eds) Calling for Help: Language and Social Interaction in Telephone Helplines Amsterdam: John Benjamin Publishing Company. pp. 133-151.

Emmison M \& S Danby 2007 "Who's the friend in the background? "Interactional strategies in determining authenticity in calls to a national children's helpline' Australian Journal of Applied Linguistics 30(1): 1-17.

Garfinkel H 1963 'A conception of, and experiments with, "trust" as a condition of stable concerted actions' in O J Harvey (ed) Motivation and social interaction: cognitive approaches. New York: Ronald Press: pp.187-238.

Garfinkel H 1967 Studies in ethnomethodology. Englewood Cliffs, N.J.: Prentice Hall.

Harris J, Danby S, Butler, C W \& M Emmison 2012 'Extending client-centered Support: Counsellors' proposals to shift from email to telephone counseling' Text and Talk 32(1): 21-37.

Heritage J 1984 Garfinkel and ethnomethodology. Cambridge, UK: Polity Press.

Heritage J 2013 'Epistemics in conversation' in T Stivers \& J Sidnell (eds) Handbook of Conversation Analysis Wiley Cambridge UK: Blackwell: pp. 370-396.

Hester S. \& P Eglin 1997 (eds) Culture-in-action: Studies in membership categorisation analysis. Washington DC: University Press of America.

Jefferson G 2004 'Glossary of transcript symbols with an introduction' in G H Lerner (ed) Conversation Analysis Studies from the First Generation Amsterdam: John Benjamins Publishing Company. pp. 13-34. 
Lamp, The 2013 Prank call with tragic consequence. 2013 70(1): 30-31. Available at: http://search.informit.com.au/documentSummary;dn=169171302068074;res=IELHEA accessed 6 May 2015.

Peräkylä A Antaki C Vehvilainen S \& I Leudar 2008 (eds) Conversation Analysis and Psychotherapy. Cambridge: Cambridge University Press.

Robinson J D 2003 'An interactional structure of medical activities during acute visits and its implications for patient participation.' Health Communication 15(1): 27-59.

Sacks H 1992 Lectures on conversation Vols. I and II. G. Jefferson (ed) Oxford: Basil Blackwell.

Sacks H 1972 'An initial investigation of the usability of conversational data for doing sociology' in D. Dusnow (ed) Studies in social interaction New York: Free Press. pp. 31-74.

Schegloff E A 2007 Sequence Organization in Interaction: A primer in Conversation Analysis Vol. 1. New York: Cambridge University Press.

Schegloff E A 1992 'Repair after next turn: The last structurally provided defense of intersubjectivity in conversation.' American Journal of Sociology 97:1295-1345.

Seilheimer M F 2011 'On doing 'being a crank caller': A look into the crank call community of practice.' Journal of Pragmatics 43: 677-690.

Stivers T 2005 'Modified repeats: One method of asserting primary rights from second position.' Research on Language and Social Interaction 38: 131-158.

Stokoe E 2012' Moving forward with membership categorization analysis: Methods for systematic analysis.' Discourse Studies 14: 277-303. 